\title{
CDISC SDTM Diagnosis Group Terminology
}

National Cancer Institute

\section{Source}

National Cancer Institute. CDISC SDTM Diagnosis Group Terminology. NCI Thesaurus.

Code C66787.

Terminology codelist used with Diagnosis Group within the Clinical Data Interchange

Standards Consortium Study Data Tabulation Model. 